\title{
RUSSIA'S REAL SECTOR OF THE ECONOMY: FACTORS AND TRENDS IN H1 2014
}

\author{
O.Izryadnova
}

In H1 2014, the business activities in the Russian economy were characterized by slowdown of growth rates of the external demand on goods of the Russian export and termination of growth in domestic demand. In H1 2014, a $2.8 \%$ reduction of investments in capital assets and the minimum growth of $2.7 \%$ in the retail trade volume in the past 4.5 years as compared to the respective period of the previous year had a negative effect on the domestic market. A positive factor of the current year was a renewal of industrial growth with advanced rates of development of manufacturing.

Slowdown of the dynamics of the Russian economy has been registered during the past 11 quarters. According to the preliminary data, in H1 2014 the growth rates of GDP and the physical volume of the output by the base types of economic activities remained at the level of the index of the previous year. In $\mathrm{H} 12014$, the negative effect of low business activities in the building and industrial complex intensified: the volume of jobs in the building sector and investments to capital assets amounted $99.4 \%$ and $97.2 \%$, respectively, as compared to $\mathrm{H} 12013$. In 2014, the economic situation is complicated by growing trends of slowdown of growth rates of retail trade turnover from the beginning of 2012. In Q2 2014, growth rates of the retail trade turnover amounted to $101.8 \%$ against the respective period of the previous year and became the minimum ones since 2010 .

A negative effect of slowdown of the consumer demand and fluctuations of the index of investment activities were partially compensated by a $1.5 \%$ growth in industrial output as compared to H1 2013. In addition to the above, a positive contribution was made by a $1.4 \%$ growth in agricultural output as compared to H1 2013. Industry and agriculture contributed much to growth in demand on infrastructure services. In 2014, transport cargo turnover increased by $1.4 \%$, thus compensating in full the reduction of $\mathrm{H} 12013$.

In $\mathrm{H} 12014$, as compared to the respective period of 2013 net export growth of $18.1 \%$ had the positive effect on economic growth (according to the preliminary data based on the SNS methods). Unlike H1 2013 when advanced growth in import against export resulted in a 5.5\% drop in the net export as compared to the index of the previous year, on the contrary, in H1 2014 a 5.1\% drop in import with a trend of growing export was registered.

In 2014, domestic demand stabilized at the level of H1 2013 with a change in the effect of factors behind its dynamics. If throughout three quarters of 2013,

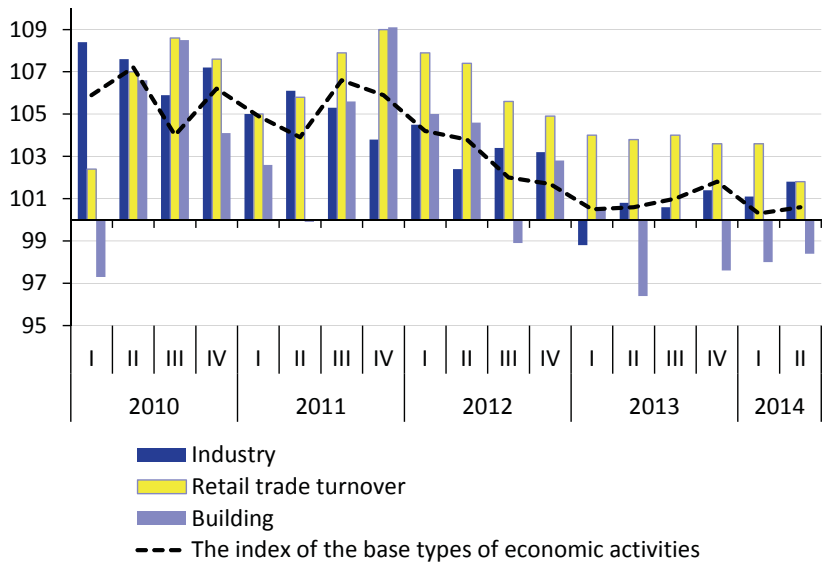

Source: Rosstat.

Fig. 1. The dynamics of the base types of economic activities in the 2011-2014 period as \% of the respective quarter of the previous year

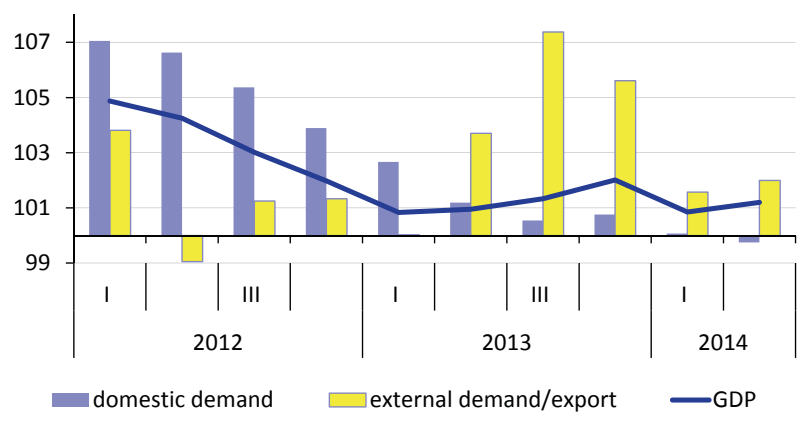

Source: Rosstat.

Fig. 2. Dynamics of GDP by components in the 2012-2014 period as \% of the respective quarter of the previous year.

advanced growth in import against the dynamics of domestic production of goods and services for the domestic market remained a dominating factor which underpinned the domestic market, from Q4 2013 the situation changed: reduction of import volumes intensified against the indices of the previous year and growth (though a weak one) in production of goods 
and services for the domestic market resumed, but it was explicitly insufficient enough to stop a quarterlong trend of shrinking of domestic demand both on the consumer and investment markets. According to the estimates of the IEP', in H2 2014 the above trends will remain and no revival of domestic demand is expected.

A decrease in financial results of enterprises and entities limits financing of investment programs by means of own funds. Investment in capital assets is based on state financing, while the inflow of direct foreign investments is insignificant. The situation is made complicated by prevalence of the capital outflow trend: in January-June 2014 capital outflow amounted to $\$ 74.6 \mathrm{bn}$ against $\$ 33.7 \mathrm{bn}$ a year before. Reduction of investments in capital assets is accompanied by a decrease in output of investment purpose goods, as well as import of such goods.

Such growth rates of consumer demand amount to $50 \%$ of the index of the previous year. In Q2 2014, trend of sudden slowdown of growth rates of retail trade volumes and paid services intensified. For the first time since 2009, on the market of food products a $0.1 \%$ reduction of demand against the index of the previous year and the minimum growth of $0.5 \%$ in demand on non-food products were observed. In June 2014, a year on year consumer inflation amounted to $107.8 \%$ against 106.9\% in 2013 (it is to be noted that prices on food products were growing at advanced rates).

It is to be noted that in 2014 there is a change in consumer behavior of households: they tend to save more with a share of expenditures on purchasing of goods reduced. The dynamics of consumer demand is largely affected by the dynamics of the real disposable income of households. In H1 2014, households' real cash income and real wages amounted to $99.8 \%$ (104.4\% a year before) and $103.3 \%$ (105.4\%), respectively, as compared to the respective period of the previous year.

In $\mathrm{H} 12014$, a renewal of the positive dynamics of the industrial output was ensured by a $2.6 \%$ growth in manufacturing as compared to the respective period of 2013. However, with the existing pattern of production, the dynamics of the domestic output depends to a large extent on the indices of production in the exportoriented sector of the economy. From Q2 2013 till the present day, production of goods and services for the external market was a factor of support of domestic production, though it is to be noted that in 2014 the dynamics of the indices of production for the domestic and external markets narrowed considerably.

In January-June 2014, growth in production remained in low-technology and medium-technology types of

1 See Scientific Bulletin of the Gaidar Institute for Economic Policy 06/14.

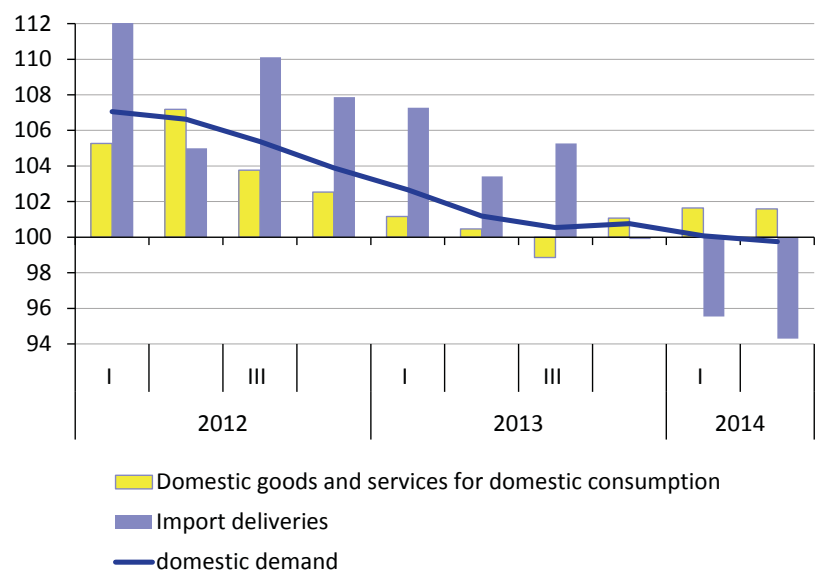

Source: Rosstat

Fig. 3. Dynamics of domestic demand by components in the 2012-2014 period as \%

of the respective period of the previous year

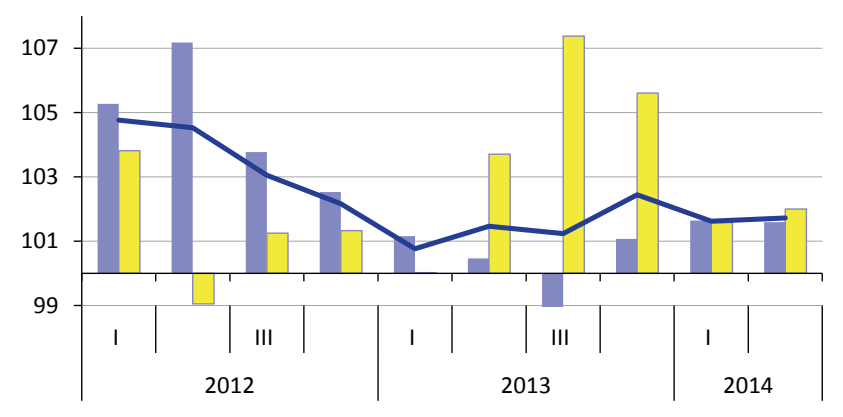

For the domestic market $\square$ For the export — Внутреннее производство

Source: Rosstat.

Fig. 4. Dynamics of domestic output of goods and services by components in the 2012-2014 period

as $\%$ of the respective quarter of the previous year

economic activities. In production of consumer goods, output of food, textile and sewing products kept growing. In the segment of goods of intermediary demand, the leaders were the chemical industry and production of rubber products and oil products. Limitation of demand affects greatly the volume of output of the high-technology complex of engineering. In H1 2014, a $9.7 \%$ drop in the output of machinery as compared to H1 2013 determined a $6.7 \%$ decrease in the output of electric, electronic and optical equipment manufacturing (which supplied component parts for engineering products of ultimate demand) as compared to JanuaryJune 2013. In H1 2014, the index of manufacturing of transport means and equipment amounted to $114.2 \%$, including $93.6 \%$ and $130.7 \%$ in the motor industry and manufacturing of ships, flying and space devices and other means of transportation, respectively, as compared to the respective period of the previous year.

Generally, in H1 2014 the total number of the unemployed in the Russian Federation amounted to 
$94.3 \%$, while the number of the officially registered unemployed, to $87.9 \%$ as compared to the respective indices of 2013. It is to be noted that the specifics of the past four years is growth in employment in the economy despite the sustained trend of slowdown of economic growth. The above is evidence of low efficiency of labor utilization. The situation is made more complicated due to both the growing unsatisfied demand on high-skilled workforce and structural imbalances. 